\title{
Unexpected ring-opening of 2,3-dihydropyridines
}

\author{
Michael-Hannes Hoffelner ${ }^{1}$ - Werner Seebacher ${ }^{1}$ (D Marcel Kaiser $^{2} \cdot$ Pascal Mäser $^{2}$ - Eva-Maria Pferschy-Wenzig ${ }^{1}$. \\ Robert Saf ${ }^{3} \cdot$ Ferdinand Belaj $^{4} \cdot$ Nadine Kretschmer $^{1} \cdot$ Muaaz Alajlani $^{5} \cdot$ Adelheid Brantner $^{1} \cdot$ Rudolf Bauer $^{1}$. \\ Robert Weis ${ }^{1}$
}

Received: 14 July 2021 / Accepted: 6 September 2021 / Published online: 16 October 2021

(c) The Author(s) 2021

\begin{abstract}
The reaction of 2,3-dihydropyridines with sulfonyl halides surprisingly yielded open chain dienes with sulfonylimine structure. The products were specific out of several possible isomers and, therefore, a separation of isomers was not necessary. All new compounds were characterized using FT-IR spectroscopy, HRMS, and NMR spectroscopy. A bicyclic by-product from the reaction of a 2,3-dihydropyridine with mesyl chloride was isolated and its structure elucidated using a single X-ray crystal analysis. Some biological activities, like antimicrobial and cytotoxic properties were investigated.
\end{abstract}

\section{Graphic abstract}<smiles>[R]N([R])C1=CC=NC(C)(C)C1</smiles><smiles>[R]N([R])C(/C=C\C)=C/C</smiles>

Keywords Sulfonylimines $\cdot$ Dienes $\cdot$ X-ray structure determination $\cdot$ Heterocycles $\cdot$ Structure elucidation $\cdot$ NMR spectroscopy

\section{Introduction}

Sulfonylimines have been described recently as important reagents and intermediates for the syntheses of heterocycles [1-3], heterocyclic arrangements [4], cycloadditions [5, 6] and asymmetric Friedel-Crafts reactions [7] as well as for

Werner Seebacher

we.seebacher@uni-graz.at

1 Institute of Pharmaceutical Sciences, University of Graz, Graz, Austria

2 Swiss Tropical and Public Health Institute and University of Basel, Basel, Switzerland

3 Institute for Chemistry and Technology of Materials (ICTM), Graz University of Technology, Graz, Austria

4 Institute of Chemistry, University of Graz, Graz, Austria

5 Institute of Pharmacy, University of Halle-Wittenberg, Halle, Germany the synthesis of natural products $[8,9]$. They were investigated for their antimicrobial [10, 11], herbicidal [12, 13], and anticancer [14] activities.

We already described some reactions of 2,3-dihydropyridines like benzylation in ring positions 1 and 3 [15-17] as well as the reaction with benzoyl halides to acyl derivatives [18] and investigated the antiprotozoal, antimicrobial, and anticancer potencies of these products [15-18]. It seems that the conjugated double bond system and a nitrogen in position 4 are important for those activities, since reduction of the double bonds to a piperidine-4-amine [16] or the hydrolysis to a keto group resulted in a complete loss of activity. To investigate how the electron density in the conjugated system influences the biological activities, we tried to connect the electron withdrawing sulfonyl group to the ring nitrogen by reaction of sulfonyl halides with 2,3-dihydropyridines. Surprisingly, the ring was cleaved and open chain sulfonylimines with diene structure were formed. 
Scheme 1<smiles>[R]N([R])C1=CC=NC(C)(C)C1</smiles>

1a: $R^{1}=R^{2}=-C_{3}$
1b: $R^{1}+R^{2}=-\left(\mathrm{CH}_{2}\right)_{4^{-}}$
1c: $R^{1}+R^{2}=-\left(\mathrm{CH}_{2}\right)_{5^{-}}$
1d: $R^{1}+R^{2}=-\left(\mathrm{CH}_{2}\right)_{6}^{-}$

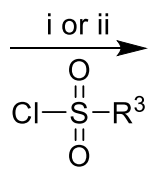<smiles>[R]N([R])C(C=NOS([R])([R])C)=CC(C)=O</smiles>

2a: $R^{3}=P h$

2b: $R^{3}=P h$

2d: $\mathrm{R}^{3}=\mathrm{Ph}$

3c: $\mathrm{R}^{3}=\mathrm{CH}_{3}$

3d: $\mathrm{R}^{3}=\mathrm{CH}_{3}$

4c: $\mathrm{R}^{3}=4-\mathrm{CIPh}$

5b: $\mathrm{R}^{3}=4 \mathrm{MePh}$ or

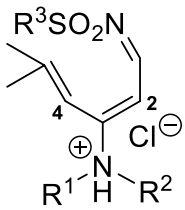

6c: $\mathrm{R}^{3}=\mathrm{Ph}$

7b: $\mathrm{R}^{3}=4-\mathrm{NO}_{2} \mathrm{Ph}$

7c: $\mathrm{R}^{3}=4-\mathrm{NO}_{2} \mathrm{Ph}$

\section{Results and discussion}

Starting compounds were the bases 1a-1d of 6-unsubstituted tetrahydropyridin-4-ylidene ammonium salts (THPS) which were prepared from their 6-methylsulfanyl analogues via selective reduction with deactivated Raney nickel [19]. During the reaction of compounds 1a-1d with alkane- or arenesulfonyl chlorides a ring cleavage occurred. If an acid scavenger like triethylamine (TEA) was used, the sulfonylimino enamines $\mathbf{2 a} \mathbf{-} \mathbf{5 b}$ were obtained, in the absence of an auxiliary base their hydrochlorides $\mathbf{6 c - 7 c}$ were isolated (Scheme 1).

As a mechanism of the ring cleavage, we assume a nucleophilic attack of the ring nitrogen at the sulfur of the sulfonyl halide. Subsequently one of the acidic protons in ring position 3 is removed by the auxiliary base or unreacted starting material. The formation of a new bond between ring atoms 2 and 3 and the cleavage between ring atom 2 and the ring nitrogen should occur simultaneously. Finally, the hydrochloride is given in acidic medium (Scheme 2).

The $E$-configuration at the double bond between C-2 and C-3 was proven by NMR spectroscopy: A cross-peak was found in a ROESY experiment between the $\mathrm{NCH}_{2}$ groups of the piperidine ring of compound $4 \mathbf{c}$ and the protons in positions 2 and 4 indicating through space interactions between these protons (Fig. 1).

To investigate if lower reaction temperatures avoids the ring opening, we conducted the reaction of $\mathbf{1 b}$ with benzene sulfonyl chloride at $-70{ }^{\circ} \mathrm{C}$ (solid $\mathrm{CO}_{2}$ /propan-2-ol). At this temperature the 4-chloro compound $\mathbf{8 b}$ was mainly formed (Scheme 3).

We investigated, therefore, the course of this reaction at different temperatures with the result, that by trend, the formation of $\mathbf{2 b}$ predominated at temperatures from -21 to
Scheme 2

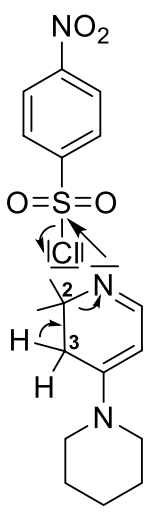<smiles>CC(C)=CC(=CC=NS(=O)(=O)c1ccc([N+](=O)[O-])cc1)[NH+]1CCCCC1</smiles>

7c

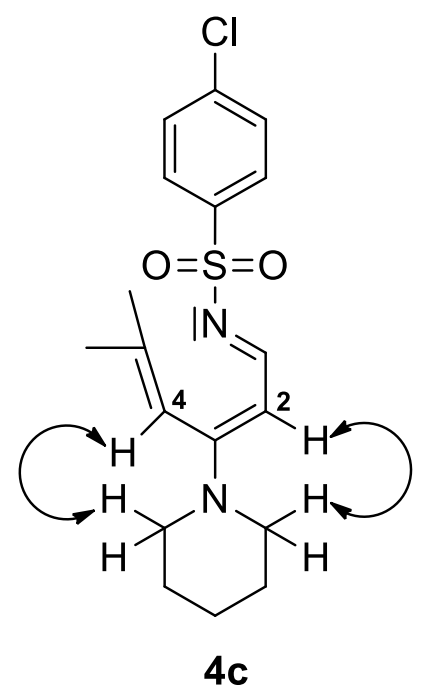

Fig. 1 NOEs observed in compound $\mathbf{4} \mathbf{c}$ indicated as arrows 


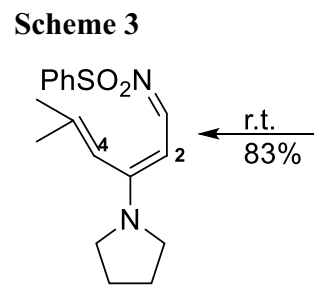

2b

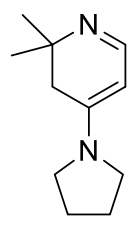

$1 b$
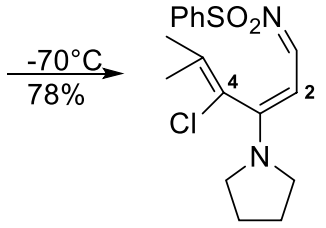

$8 b$

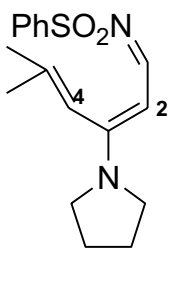

2b

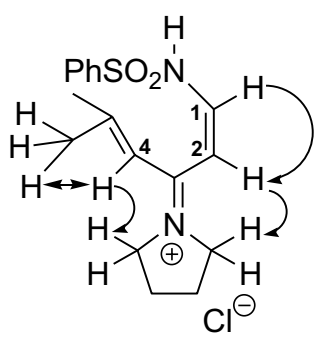

$9 b$
Table 1 Percentages of products $\mathbf{2 b}$ and $\mathbf{8 b}$ in dependency of reaction temperature

\begin{tabular}{lll}
\hline Temperature & $\mathbf{2 b}^{\mathrm{a}}$ & $\mathbf{8 b}^{\mathrm{a}}$ \\
\hline$-70{ }^{\circ} \mathrm{C}$ & 20 & 80 \\
$-66{ }^{\circ} \mathrm{C}$ & 15 & 85 \\
$-40{ }^{\circ} \mathrm{C}$ & 69 & 31 \\
$-26{ }^{\circ} \mathrm{C}$ & 71 & 29 \\
$-21{ }^{\circ} \mathrm{C}$ & 81 & 19 \\
$-7{ }^{\circ} \mathrm{C}$ & 77 & 23 \\
$0{ }^{\circ} \mathrm{C}$ & 85 & 15 \\
$20{ }^{\circ} \mathrm{C}$ & 86 & 14 \\
\hline
\end{tabular}

${ }^{\mathrm{a}}$ Values were determined using ${ }^{1} \mathrm{H}$ NMR spectroscopy of the raw products and are $\mathrm{mol} \%$ $20^{\circ} \mathrm{C}$, whereas its 4-chloro analogue $8 \mathbf{b}$ was formed as main product at very low temperatures like $-66^{\circ} \mathrm{C}$ and $-70{ }^{\circ} \mathrm{C}$ (Table 1).

The contrast of the yields determined using ${ }^{1} \mathrm{H}$ NMR spectroscopy to the isolated yields is a result of extensive cleaning procedures including repeated purification using $\mathrm{CC}$ as well as repeated crystallization. Only pure fractions were considered for the calculation of yields in the experimental part. Mixed fractions as well as mother liquors were not further separated.

During the attempts to form a hydrochloride of $\mathbf{2 b}$, an isomerization of the double bond system to $\mathbf{9 b}$ was observed. Due to this positional change of the double bond we observed the following shifts of signals in ${ }^{13} \mathrm{C}$ NMR spectra of $\mathbf{9 b}$ compared to the hydrochlorides $\mathbf{6 c}, \mathbf{7 b}$, and 7c: the signals of C-3 and C-5 were shifted 3-4 ppm downfield, whereas, the resonance of $\mathrm{C}-1$ shifted $17 \mathrm{ppm}$ to lower frequencies. Furthermore, we observed a separation of the $\mathrm{NCH}_{2}$ signals in ${ }^{1} \mathrm{H}$ NMR spectra due to the loss of rotatability caused by the formed double bond (Fig. 2).

The Z-configuration of the double bond in position 1 of compound $\mathbf{9 b}$ was confirmed by NOE-measurements. NOEs where observed between $\mathrm{H}-1$ and $\mathrm{H}-2$ as well as between H-2 and a proton of the $\mathrm{NCH}_{2}$ group of the pyrrolidine ring. Furthermore $\mathrm{H}-4$ and the protons of a methyl group and $\mathrm{H}-4$ and a proton of the other $\mathrm{NCH}_{2}$ group showed through space interactions (Fig. 2). Surprisingly, the bicyclic by-product 10c was isolated as by-product from the reaction of $\mathbf{1 c}$ with mesyl
Fig. 2 Structures of compounds $\mathbf{2 b}$ and $\mathbf{9 c}$, NOEs indicated as arrows

Fig. 3 Structure of compound 10c<smiles>CC1(C)C(S(C)(=O)=O)=C(N2CCCCC2)C2C=C(S(C)(=O)=O)N(S(C)(=O)=O)C1C2</smiles>

chloride. A single X-ray crystal analysis revealed $10 \mathrm{c}$ to be (1RS,4RS)-6,6-dimethyl-5-(methanesulfonyl)-7-(piperidin1-yl)-2 $\lambda^{6}$-thia-5-azabicyclo[2.2.2] oct-7-en-2,2-dione. So far no compounds with a 2-thia-5-azabicyclo[2.2.2]octane ring system have been published (Fig. 3).

All atoms lie on general positions. The asymmetric unit consists of two molecules (s. Figs. 4, 5) showing very similar geometric parameters.

In addition to the two molecules in $1 R, 4 R$ configurations there exist two molecules in $1 S, 4 S$ configurations in the unit cell related by inversion centers (Fig. 6).

Since, as already mentioned, some sulfonylimines showed antimicrobial and anticancer activities, we investigated some of them for their activities against Plasmodium falciparum as well as Trypanosoma brucei rhodesiense, which are the causative organisms of malaria tropica and sleeping sickness, respectively. Moreover, their cytotoxic properties were examined. All of the tested compounds are completely inactive against both parasites. The results are presented in Table 2.

In addition to that, we investigated the anticancer activity of compounds $2 \mathbf{a}, \mathbf{2 b}, \mathbf{3 c}, \mathbf{4 c}, \mathbf{7 b}$, and $9 \mathbf{b}$ at $5 \mu \mathrm{M}$ and $50 \mu \mathrm{M}$ concentration against human leukemia cells (CCRF-CEM). The activities are shown in Fig. 7. The compounds clearly show more inhibitory activity at $50 \mu \mathrm{M}$ concentration, but their inhibitory potential is low.

The investigation of the activities against some bacteria and yeast was done using drop plate methods. The results are presented in Table 3. Activity against the following 
Fig. 4 Stereoscopic ORTEP [20] plot of molecule A of 10c showing the atomic numbering scheme. The probability ellipsoids are drawn at the 50\% probability level. The $\mathrm{H}$ atoms of the methyl groups and those of the piperidine ring were omitted for clarity, the other $\mathrm{H}$ atoms were drawn with arbitrary radii

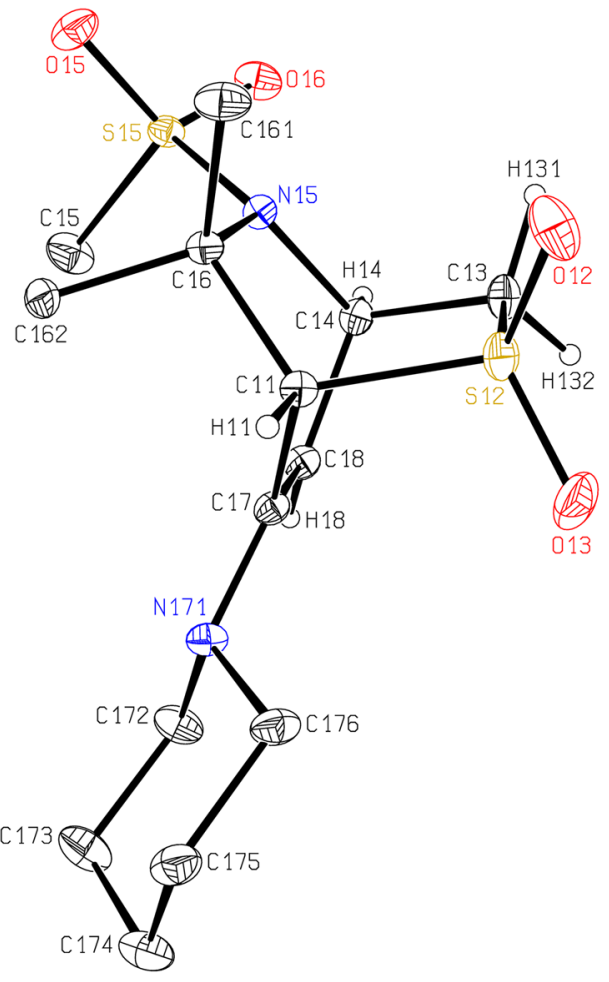

Fig. 5 Stereoscopic ORTEP [20] plot of molecule B of 10c showing the atomic numbering scheme. The probability ellipsoids are drawn at the 50\% probability level. The $\mathrm{H}$ atoms of the methyl groups and those of the piperidine ring were omitted for clarity, the other $\mathrm{H}$ atoms were drawn with arbitrary radii

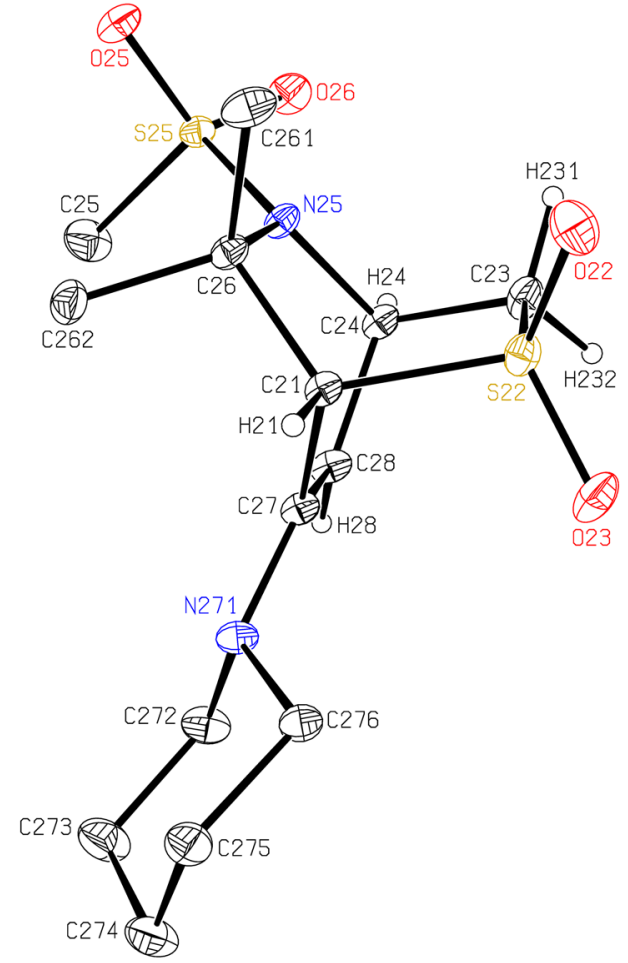

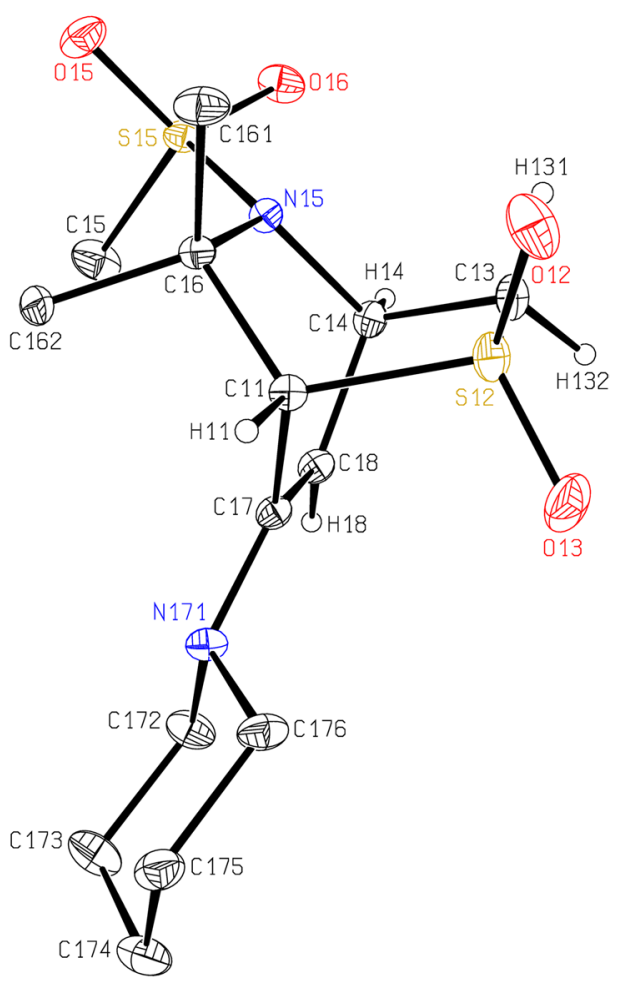

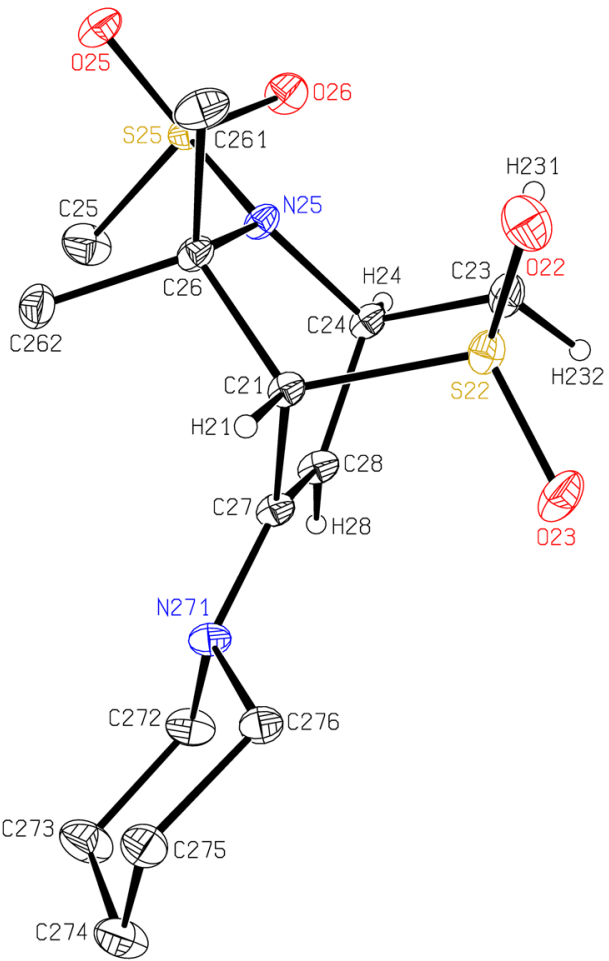

organisms was determined: Bacillus subtilis wild-type 168 (Bac. sub.), Anthrobacter aurescens DSM20116 (Anth. aur.), Escherichia coli K12 (E. coli), Pseudomonas aeruginosa DSM50090 (P. aerug.), and Candida krusei CCMM L10 (Cand. krus.). All of the tested compounds show distinct activity against Anthrobacter aurescens and also potency against the yeast Candida krusei.

Interestingly, compound $\mathbf{9 b}$, the hydrochloride of $\mathbf{2 b}$ with shifted double bonds, showed activity against all of the investigated organisms. Especially, the potency against the 
Fig. 6 Unit cell in the crystal of 10c

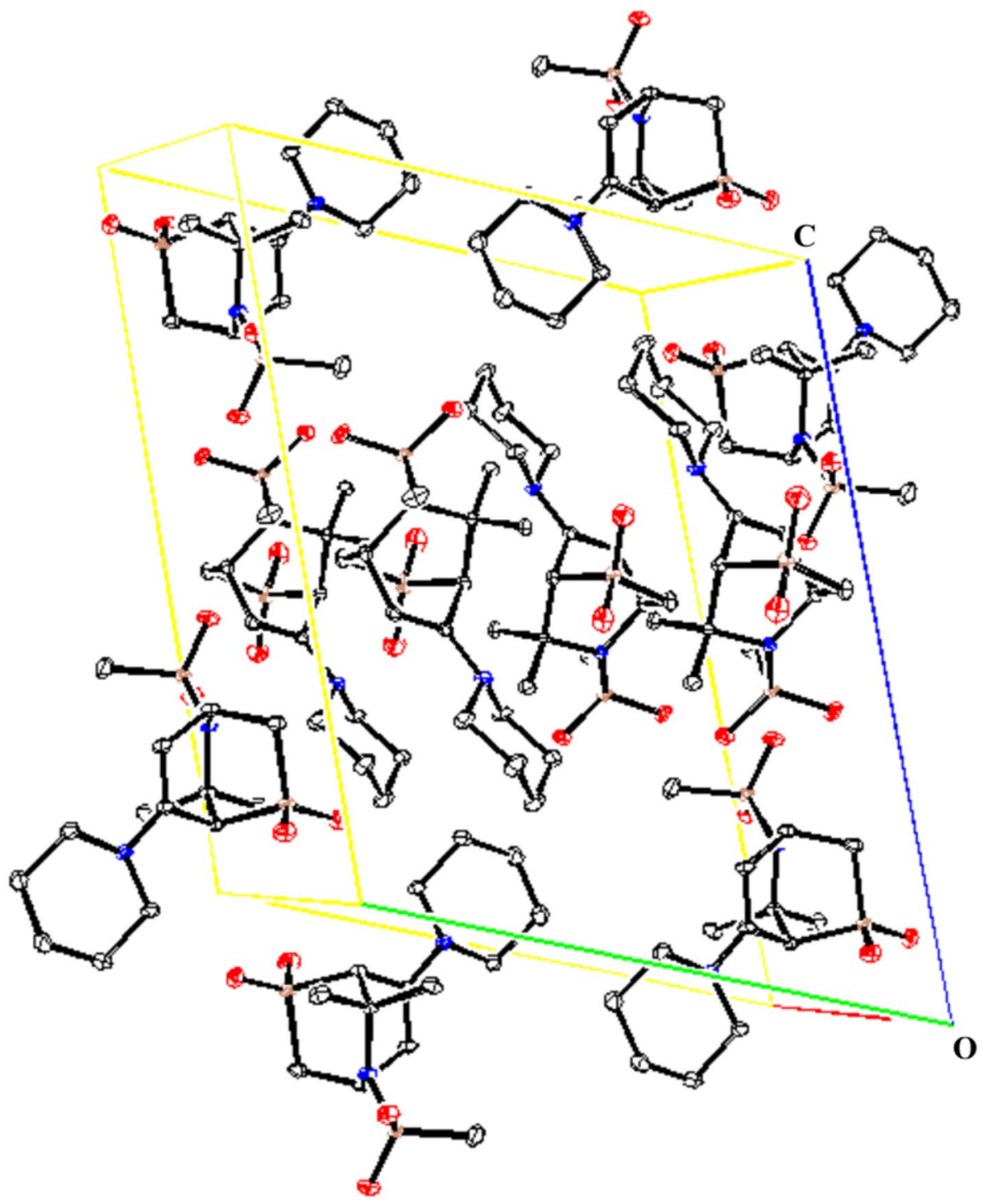

Table 2 Antiprotozoal and cytotoxic activities of $\mathbf{7 b}-\mathbf{1 0 c}\left(\mathrm{IC}_{50}\right.$ values in $\mu \mathrm{M}$ )

\begin{tabular}{llll}
\hline Cpd & $\begin{array}{l}\text { L6 cells } \\
\mathrm{IC}_{50}{ }^{\mathrm{a}}\end{array}$ & $\begin{array}{l}\text { P. falc. NF54 } \\
\mathrm{IC}_{50}{ }^{\mathrm{a}}\end{array}$ & $\begin{array}{l}\text { T. } \text { b. rhod } \\
\mathrm{IC}_{50}{ }^{\mathrm{a}}\end{array}$ \\
\hline $\mathbf{7 b}$ & $>250$ & 37.9 & 132 \\
$\mathbf{7 c}$ & 207 & 51.3 & 177 \\
$\mathbf{8 b}$ & $>283$ & 105 & 173 \\
$\mathbf{9 b}$ & 182 & 48.2 & 282 \\
$\mathbf{1 0 c}$ & 5.31 & 11.4 & 7.36 \\
$\mathrm{Mel}^{\mathrm{b}}$ & 7.78 & & 0.0039 \\
$\mathrm{CQ}^{\mathrm{c}}$ & 116.9 & 0.007 & \\
$\mathrm{P}^{\mathrm{d}}$ & 0.012 & & \\
\hline
\end{tabular}

${ }^{a}$ Values represent the average of four determinations (two determinations of two independent experiments) indicated in $\mu \mathrm{M}$

${ }^{\mathrm{b}} \mathrm{Mel}$, melarsoprol

${ }^{\mathrm{c}} \mathrm{CQ}$, chloroquine diphosphate

${ }^{\mathrm{d}} \mathrm{P}$ podophyllotoxin

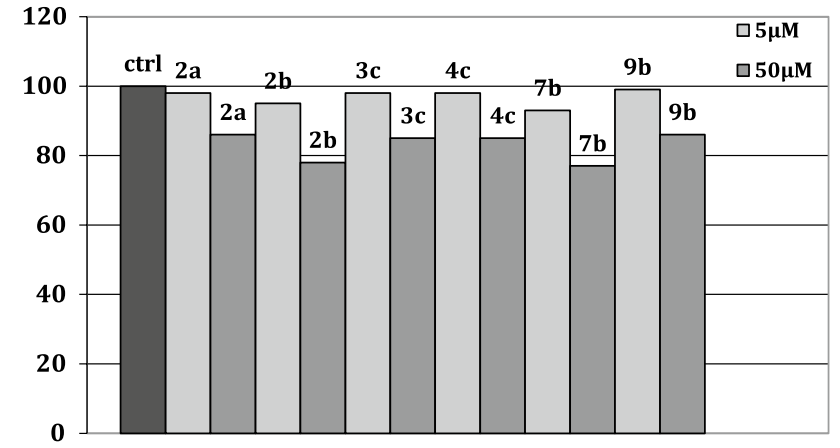

Fig. 7 Anticancer activity of $\mathbf{2 a}, \mathbf{2 b}, \mathbf{3 c}, \mathbf{4 c}, \mathbf{7 b}$, and $9 \mathbf{b}$ against CCRF-CEM cells as percentages of metabolic active cells compared to the control 
Table 3 Antimicrobial activities of $2 \mathbf{2 a}, \mathbf{2 b}, \mathbf{3 c}, \mathbf{4 c}, \mathbf{5 b}, \mathbf{7 b}$, and $9 \mathbf{b}$

\begin{tabular}{llllll}
\hline Cpd & Bac. sub & Anth. aur & E. coli & P. aerug & Cand. krus \\
\hline $2^{\mathrm{a}}$ & - & ++ & - & - & + \\
$\mathrm{2b}$ & - & ++ & - & - & + \\
$3 \mathrm{c}$ & - & ++ & - & - & + \\
$4 \mathrm{c}$ & - & ++ & - & - & + \\
$5 \mathrm{~b}$ & - & ++ & - & - & + \\
$7 \mathrm{~b}$ & - & ++ & - & - & + \\
$9 \mathrm{~b}$ & ++ & ++ & + & ++ & ++ \\
\hline
\end{tabular}

No clearance $=$ inactive $(-)$, clearance $=$ active $(+)$ and clear clearance $=$ higher activity $(++)$

Gram-negative, aerobic, rod shaped bacterium Pseudomonas aeruginosa is noteworthy, since this pathogenic germ is one of the opportunistic pathogens, which is the main cause of prevalent hospital infections worldwide [21].

\section{Conclusion}

The reaction of 2,3-dihydropyridines yielded unexpected sulfonylimines with diene structure. As a side product, $(1 R S, 4 R S)$-6,6-dimethyl-5-(methylsulfonyl)-7-(piperidin1 -yl)- $2 \lambda^{6}$-thia-5-azabicyclo[2.2.2] oct-7-en-2,2-dione was isolated whose structure was established with the aid of a single X-ray crystal analysis. The new sulfonylimines were investigated for some antimicrobial and cytotoxic activities. One compound showed distinct activity against Pseudomonas aeruginosa. Therefore, further investigations and optimizations of new sulfonylimines will be done to increase the antibacterial activity.

\section{Experimental}

Melting points were obtained on a digital melting point apparatus Electrothermal IA 9200. IR spectra: Bruker Alpha Platinum ATR FT-IR spectrometer ( $\mathrm{KBr}$ discs). NMR spectra: Bruker Ascend 400, $5 \mathrm{~mm}$ tubes, spectra were acquired in $\mathrm{CDCl}_{3}$ containing $0.03 \%$ TMS. Chemical shifts were recorded in parts per million (ppm), for ${ }^{1} \mathrm{H}$ spectra TMS $(0.00 \mathrm{ppm})$ was used as internal standard and for ${ }^{13} \mathrm{C}$ spectra the central peak of the $\mathrm{CDCl}_{3}$ peak was used as the internal reference $(77.0 \mathrm{ppm})$. Some spectra were acquired in DMSO- $d_{6}$. In this case the central peaks of the DMSO- $d_{5}$ signal at $2.49 \mathrm{ppm}$ in ${ }^{1} \mathrm{H}$ spectra and at $39.7 \mathrm{ppm}$ in ${ }^{13} \mathrm{C}$ spectra served as internal reference. Abbreviations: aromatic $\mathrm{H}, \mathrm{ArH}$; aromatic $\mathrm{C}, \mathrm{ArC}$, quaternary aromatic $\mathrm{C}, \mathrm{ArC}_{\mathrm{q}}$. Signal multiplicities are abbreviated as follows: s, singlet; d, doublet; dd, doubledoublet; ddd, doubledoubledoublet; dt, doubletriplet; t, triplet; m, multiplet; br, broad. Coupling constants $(J)$ are reported in Hertz $(\mathrm{Hz}) .{ }^{1} \mathrm{H}$ and ${ }^{13} \mathrm{C}$ resonances were assigned using ${ }^{1} \mathrm{H},{ }^{1} \mathrm{H}$ - and ${ }^{1} \mathrm{H},{ }^{13} \mathrm{C}$-correlation spectra. ${ }^{1} \mathrm{H}$ and ${ }^{13} \mathrm{C}$ resonances are numbered as given in the formulae. HRMS: Micromass tofspec 3E spectrometer (MALDI), GCT-Premier, Waters (EI, $70 \mathrm{eV}$ ), Q Exactive Hybrid Quadrupole-Orbitrap mass spectrometer, Thermo Fisher Scientific (HESI, $3.5 \mathrm{kV}$ ). Materials: column chromatography (CC): silica gel 60 (Merck 70-230 mesh, porediameter $0.6 \mathrm{~nm}$ ), aluminum oxide (Alox) basic (Fluka for chromatography, $0.05-0.15 \mathrm{~mm}$, Brockmann activity I, basic); Alox neutral 90 (Merck, 0.063-0.2 mm, activity I, neutral); thin-layer chromatography (TLC): TLC plates (Merck, silica gel $60 \mathrm{~F}_{254} 0.2 \mathrm{~mm}, 200 \times 200 \mathrm{~mm}$ ); TLC plates (Merck, Alox $60 \mathrm{~F}_{254}$ neutral, $200 \times 200 \mathrm{~mm}$ ); the substances were detected in UV light at $254 \mathrm{~nm}$. If no stationary phase is mentioned (CC and TLC) the separation took place using silica gel.

The preparation of the hydroiodides of compounds 1a-1d was already reported by us [19]. The bases were set free by shaking with $2 \mathrm{M} \mathrm{NaOH}$ and subsequent extraction with $\mathrm{CHCl}_{3}$ and used as starting materials without further purification.

\section{Preparation of compounds $\mathbf{2 a}-\mathbf{5 b}$}

The bases 1a-1d were co-distilled twice with dry benzene and dissolved in dry dichloromethane. To this solution, dry triethylamine (TEA) and the corresponding arene- or alkanesulfonyl chloride was added. The reaction mixture was put under an Argon atmosphere and stirred at room temperature. Water was added and the mixture was stirred for $15 \mathrm{~min}$ and put into a separatory funnel. The organic layer was separated and the aqueous layer extracted five times with dichloromethane. The combined organic layers were dried over anhydrous sodium sulfate and filtered. The solvent was evaporated in vacuo and the residue was co-distilled twice with benzene and further purified.

( $2 E)-N-$ [ 3 - (Dimethyla mino) - 5 - methylhexa-2,4-dien-1-ylidene]benzenesulfonamide (2a, $\mathrm{C}_{15} \mathrm{H}_{20} \mathrm{~N}_{2} \mathrm{O}_{2} \mathrm{~S}$ ) Reaction of $573 \mathrm{mg}$ of $1 \mathrm{a}(3.76 \mathrm{mmol})$ in 33 $\mathrm{cm}^{3}$ of $\mathrm{CH}_{2} \mathrm{Cl}_{2}$ with $698 \mathrm{mg}$ of benzenesulfonyl chloride ( $3.95 \mathrm{mmol})$ in the presence of $1.141 \mathrm{~g}$ of TEA $(11.28 \mathrm{mmol})$ yielded after $4 \mathrm{~d}$ a residue which was purified by $\mathrm{CC}$ using $\left(\mathrm{CH}_{2} \mathrm{Cl}_{2}: \mathrm{MeOH}=30: 1\right)$ as eluent. Fractions containing the product were combined, evaporated and the residue recrystallized twice from ethyl acetate/cyclohexane. Fractions containing the product and impurities were combined, evaporated, and recrystallized thrice from ethyl acetate/acetone. Yield: $175 \mathrm{mg}$ (16\%) of $\mathbf{2 a}$ as a white cotton-like solid. $R_{\mathrm{f}}=0.23\left(\mathrm{CH}_{2} \mathrm{Cl}_{2}: \mathrm{MeOH}=30: 1\right)$; m.p.: $93{ }^{\circ} \mathrm{C}$ (ethyl acetate/ cyclohexane); ${ }^{1} \mathrm{H}$ NMR (DMSO- $\left.d_{6}, 400 \mathrm{MHz}\right): \delta=1.48(\mathrm{~d}$, $\left.J=1.2 \mathrm{~Hz}, 3 \mathrm{H}, \mathrm{CH}_{3}\right), 1.89\left(\mathrm{~d}, J=1.5 \mathrm{~Hz}, 3 \mathrm{H}, \mathrm{CH}_{3}\right), 3.04(\mathrm{~s}$, 
$\left.3 \mathrm{H}, \mathrm{NCH}_{3}\right), 3.06\left(\mathrm{~s}, 3 \mathrm{H}, \mathrm{NCH}_{3}\right), 5.41(\mathrm{~d}, J=11.1 \mathrm{~Hz}, 1 \mathrm{H}$, $\mathrm{H}-2), 5.87$ (t, $J=1.5 \mathrm{~Hz}, 1 \mathrm{H}, \mathrm{H}-4), 7.48-7.58$ (m, 3H, ArH), 7.65-7.68 (m, 2H, ArH), 8.10 (d, $J=11.1 \mathrm{~Hz}, 1 \mathrm{H}, \mathrm{H}-1) \mathrm{ppm}$; ${ }^{13} \mathrm{C}$ NMR (DMSO- $\left.d_{6}, 100 \mathrm{MHz}\right): \delta=20.10\left(\mathrm{CH}_{3}\right), 24.99$ $\left(\mathrm{CH}_{3}\right), 39.79,41.44\left(2 \mathrm{NCH}_{3}\right), 96.51(\mathrm{C}-2), 117.34(\mathrm{C}-4)$, 126.29, 129.14, $131.86(\mathrm{ArC}), 142.65\left(\mathrm{ArC}_{\mathrm{q}}\right), 143.74(\mathrm{C}-5)$, 167.81 (C-3), 168.03 (C-1) ppm; IR (KBr): $\bar{v}=2927,1558$, 1448, 1407, 1344, 1321, 1297, 1284, 1248, 1145, 1086, 891, 804, $725 \mathrm{~cm}^{-1}$; HRMS $\left(\mathrm{EI}^{+}\right): \mathrm{m} / z$ calcd. $\mathrm{C}_{15} \mathrm{H}_{20} \mathrm{~N}_{2} \mathrm{O}_{2} \mathrm{~S}\left(\mathrm{M}^{+}\right)$ 292.1245 , found 292.1256 .

(2E)- $N$-[5-Methyl-3-(pyrrolidin-1-yl)hexa-2,4-dien-1-ylidene]benzenesulfonamide $\left(2 \mathrm{~b}, \mathrm{C}_{17} \mathrm{H}_{22} \mathrm{~N}_{2} \mathrm{O}_{2} \mathrm{~S}\right)$ Reaction of $553 \mathrm{mg}$ of $1 \mathbf{b}(3.1 \mathrm{mmol})$ in $30 \mathrm{~cm}^{3}$ of $\mathrm{CH}_{2} \mathrm{Cl}_{2}$ with $548 \mathrm{mg}$ of benzenesulfonyl chloride $(3.1 \mathrm{mmol})$ in the presence of $628 \mathrm{mg}$ of TEA $(6.2 \mathrm{mmol})$ yielded after $2 \mathrm{~d}$ a residue which was purified by twofold $\mathrm{CC}$ using $\left(\mathrm{CH}_{2} \mathrm{Cl}_{2}: \mathrm{MeOH}=40: 1\right)$ as eluent. Yield: $95 \mathrm{mg}(10 \%)$ of $\mathbf{2 b}$ as yellow resin. $R_{\mathrm{f}}=0.13$ $\left(\mathrm{CH}_{2} \mathrm{Cl}_{2}: \mathrm{MeOH}=40: 1\right) ;{ }^{1} \mathrm{H}$ NMR (DMSO- $\left.d_{6}, 400 \mathrm{MHz}\right)$ : $\delta=1.51\left(\mathrm{~d}, J=1.2 \mathrm{~Hz}, 3 \mathrm{H}, \mathrm{CH}_{3}\right), 1.77-1.97\left(\mathrm{~m}, 4 \mathrm{H}, 2 \mathrm{CH}_{2}\right)$, $1.88\left(\mathrm{~d}, J=1.4 \mathrm{~Hz}, 3 \mathrm{H}, \mathrm{CH}_{3}\right), 3.21-3.58\left(\mathrm{~m}, 4 \mathrm{H}, 2 \mathrm{NCH}_{2}\right)$, $5.30(\mathrm{~d}, J=11.2 \mathrm{~Hz}, 1 \mathrm{H}, \mathrm{H}-2), 5.91(\mathrm{t}, J=1.5 \mathrm{~Hz}, 1 \mathrm{H}$, $\mathrm{H}-4)$, 7.47-7.57 (m, 3H, ArH), 7.64-7.69 (m, 2H, ArH), $8.09(\mathrm{~d}, J=11.2 \mathrm{~Hz}, 1 \mathrm{H}, \mathrm{H}-1) \mathrm{ppm} ;{ }^{13} \mathrm{C}$ NMR (DMSO- $d_{6}$, $100 \mathrm{MHz}): \delta=20.20\left(\mathrm{CH}_{3}\right), 24.51,24.77\left(2 \mathrm{CH}_{2}\right), 25.10$ $\left(\mathrm{CH}_{3}\right), 48.79,50.23\left(2 \mathrm{NCH}_{2}\right), 97.12(\mathrm{C}-2), 117.75(\mathrm{C}-4)$, 126.24, 129.12, 131.79 (ArC), $142.83\left(\mathrm{ArC}_{\mathrm{q}}\right), 143.26(\mathrm{C}-5)$, 165.02 (C-3), 167.09 (C-1) ppm; IR (KBr): $\bar{v}=2973,1558$, 1537, 1448, 1352, 1313, 1297, 1283, 1243, 1142, 1085, 885, $805,791,725 \mathrm{~cm}^{-1}$; HRMS $\left(\mathrm{EI}^{+}\right): \mathrm{m} / z$ calcd. $\mathrm{C}_{17} \mathrm{H}_{22} \mathrm{~N}_{2} \mathrm{O}_{2} \mathrm{~S}$ $\left(\mathrm{M}^{+}\right)$318.1402, found 318.1437.

(2E)- $\mathrm{N}$-[5-Methyl-3-(azepan-1-yl)hexa-2,4-dien-1-ylidene]benzenesulfonamide $\left(2 \mathrm{~d}, \mathrm{C}_{19} \mathrm{H}_{26} \mathrm{~N}_{2} \mathrm{O}_{2} \mathrm{~S}\right)$ Reaction of $730 \mathrm{mg}$ of $1 \mathrm{~d}(3.54 \mathrm{mmol})$ in $31 \mathrm{~cm}^{3}$ of $\mathrm{CH}_{2} \mathrm{Cl}_{2}$ with $657 \mathrm{mg}$ of benzenesulfonyl chloride $(3.72 \mathrm{mmol})$ in the presence of $1.074 \mathrm{~g}$ of TEA $(10.6 \mathrm{mmol})$ yielded after $1 \mathrm{~d}$ a residue which was purified by $\mathrm{CC}$ using $\left(\mathrm{CH}_{2} \mathrm{Cl}_{2}: \mathrm{MeOH}=30: 1\right)$ as eluent. Fractions containing the product were combined, evaporated and the residue recrystallized twice from ethyl acetate/cyclohexane. Yield: $58 \mathrm{mg}(5 \%)$ of $\mathbf{2 d}$ as white needles. $R_{\mathrm{f}}=0.32\left(\mathrm{CH}_{2} \mathrm{Cl}_{2}: \mathrm{MeOH}=30: 1\right)$; m.p.: $132{ }^{\circ} \mathrm{C} ;{ }^{1} \mathrm{H}$ NMR (DMSO- $\left.d_{6}, 400 \mathrm{MHz}\right): \delta=1.35-1.76\left(\mathrm{~m}, 8 \mathrm{H}, 4 \mathrm{CH}_{2}\right)$, $1.48\left(\mathrm{~s}, 3 \mathrm{H}, \mathrm{CH}_{3}\right), 1.88\left(\mathrm{~s}, 3 \mathrm{H}, \mathrm{CH}_{3}\right), 3.39-3.64(\mathrm{~m}, 4 \mathrm{H}$, $\left.2 \mathrm{NCH}_{2}\right), 5.46(\mathrm{~d}, J=11.0 \mathrm{~Hz}, 1 \mathrm{H}, \mathrm{H}-2), 5.92(\mathrm{~s}, 1 \mathrm{H}, \mathrm{H}-4)$, 7.49-7.68 (m, 5H, ArH), 8.10 (d, $J=11.0 \mathrm{~Hz}, 1 \mathrm{H}, \mathrm{H}-1) \mathrm{ppm}$; ${ }^{13} \mathrm{C}$ NMR (DMSO- $\left.d_{6}, 100 \mathrm{MHz}\right): \delta=20.25\left(\mathrm{CH}_{3}\right), 24.98$ $\left(\mathrm{CH}_{3}\right), 25.28,25.55,26.44,28.45\left(4 \mathrm{CH}_{2}\right), 50.22,52.12$ $\left(2 \mathrm{NCH}_{2}\right), 96.11(\mathrm{C}-2), 117.16(\mathrm{C}-4), 126.37,129.19,131.93$ (ArC), $142.53\left(\mathrm{ArC}_{\mathrm{q}}\right), 143.41$ (C-5), 167.17 (C-3), 168.47 (C-1) ppm; IR (KBr): $\bar{v}=2928,1551,1348,1306,1283$, 1245, 1142, 1084, 875, 791, 766, $725 \mathrm{~cm}^{-1}$; HRMS $\left(\mathrm{EI}^{+}\right)$: $\mathrm{m} / z$ calcd. $\mathrm{C}_{19} \mathrm{H}_{26} \mathrm{~N}_{2} \mathrm{O}_{2} \mathrm{~S}\left(\mathrm{M}^{+}\right) 346.1715$, found 346.1714 .
(2E)- $N$-[5-Methyl-3-(piperidin-1-yl)hexa-2,4-dien-1-ylidene]methanesulfonamide $\left(3 \mathrm{C}, \quad \mathrm{C}_{13} \mathrm{H}_{22} \mathrm{~N}_{2} \mathrm{O}_{2} \mathrm{~S}\right)$ and (1RS,4RS)-()-6,6-dimethyl-5-(methanesulfonyl)-7-(piperidin-1-yl)-2 $\lambda^{6}$-thia-5-azabicyclo[2.2.2]oct-7-en-2,2-dione (10c, $\left.\mathrm{C}_{14} \mathrm{H}_{24} \mathrm{~N}_{2} \mathrm{O}_{4} \mathrm{~S}_{2}\right)$ Reaction of $862 \mathrm{mg}$ of $1 \mathrm{c}(4.48 \mathrm{mmol})$ in 39 $\mathrm{cm}^{3}$ of $\mathrm{CH}_{2} \mathrm{Cl}_{2}$ with $539 \mathrm{mg}$ of methanesulfonyl chloride ( $4.70 \mathrm{mmol})$ in the presence of $1.36 \mathrm{~g}$ of TEA $(13.4 \mathrm{mmol})$ yielded overnight a residue which was purified by $\mathrm{CC}$ over basic aluminum oxide using $\left(\mathrm{CH}_{2} \mathrm{Cl}_{2}: \mathrm{MeOH}=70: 1\right)$ as eluent. Fractions containing the products were combined and evaporated. A second $\mathrm{CC}$ of the residue using $\left(\mathrm{CH}_{2} \mathrm{Cl}_{2}: \mathrm{MeOH}=30: 1\right)$ as eluent followed. Fractions containing the product $3 \mathbf{c}$ were combined and evaporated. Yield: $35 \mathrm{mg}(3 \%)$ of $\mathbf{3 c}$ as yellow resin. The fractions containing 10c were combined and evaporated. The residue was purified by $\mathrm{CC}$ over aluminum oxide using $\mathrm{CH}_{2} \mathrm{Cl}_{2}$ as eluent giving $36 \mathrm{mg}$ of 10c (2\%) as white foam. For X-ray crystal analysis it was crystallized from ethanol giving colorless crystals.

Compound 3c: $R_{\mathrm{f}}=0.21\left(\mathrm{CH}_{2} \mathrm{Cl}_{2}: \mathrm{MeOH}=30: 1\right) ;{ }^{1} \mathrm{H}$ NMR (DMSO- $\left.d_{6}, 400 \mathrm{MHz}\right): \delta=1.40-1.67\left(\mathrm{~m}, 6 \mathrm{H}, 3 \mathrm{CH}_{2}\right)$, $1.57\left(\mathrm{~s}, 3 \mathrm{H}, \mathrm{CH}_{3}\right), 1.89\left(\mathrm{~s}, 3 \mathrm{H}, \mathrm{CH}_{3}\right), 2.76\left(\mathrm{~s}, 3 \mathrm{H}, \mathrm{SO}_{2} \mathrm{CH}_{3}\right)$, $3.51\left(\mathrm{br}, \mathrm{s}, 4 \mathrm{H}, 2 \mathrm{NCH}_{2}\right), 5.55(\mathrm{~d}, J=10.8 \mathrm{~Hz}, 1 \mathrm{H}, \mathrm{H}-2)$, 5.87 (s, $1 \mathrm{H}, \mathrm{H}-4), 8.16(\mathrm{~d}, J=10.8 \mathrm{~Hz}, 1 \mathrm{H}, \mathrm{H}-1) \mathrm{ppm} ;{ }^{13} \mathrm{C}$ NMR (DMSO- $\left.d_{6}, 100 \mathrm{MHz}\right): \delta=20.12\left(\mathrm{CH}_{3}\right), 23.81\left(\mathrm{CH}_{2}\right)$, $24.97\left(\mathrm{CH}_{3}\right), 25.49,26.59\left(2 \mathrm{CH}_{2}\right), 41.45\left(\mathrm{SO}_{2} \mathrm{CH}_{3}\right), 47.68$, $50.27\left(2 \mathrm{NCH}_{2}\right), 95.31(\mathrm{C}-2), 117.41(\mathrm{C}-4), 143.50(\mathrm{C}-5)$, 165.50 (C-3), 168.73 (C-1) ppm; IR (KBr): $\bar{v}=2942,1556$, 1445, 1348, 1324, 1310, 1282, 1242, 1118, 955, 878, 811, $777 \mathrm{~cm}^{-1}$; HRMS $\left(\mathrm{EI}^{+}\right): \mathrm{m} / z$ calcd. $\mathrm{C}_{13} \mathrm{H}_{22} \mathrm{~N}_{2} \mathrm{O}_{2} \mathrm{~S}\left(\mathrm{M}^{+}\right)$ 270.1402 , found 270.1425 .

Compound 10c: $R_{\mathrm{f}}=0.70\left(\mathrm{CH}_{2} \mathrm{Cl}_{2}: \mathrm{MeOH}=30: 1\right) ;$ m.p.: $163{ }^{\circ} \mathrm{C} ;{ }^{1} \mathrm{H}$ NMR $\left(\mathrm{CDCl}_{3}, 400 \mathrm{MHz}\right): \delta=1.45(\mathrm{~s}, 3 \mathrm{H}$, $\left.\mathrm{CH}_{3}\right), 1.56-1.66\left(\mathrm{~m}, 6 \mathrm{H}, 3 \mathrm{CH}_{2}\right), 1.97\left(\mathrm{~s}, 3 \mathrm{H}, \mathrm{CH}_{3}\right), 2.93$ (s, $3 \mathrm{H}, \mathrm{SO}_{2} \mathrm{CH}_{3}$ ), 2.94-3.08 (m, 4H, $2 \mathrm{NCH}_{2}$ ), 3.14 (ddd, $J=12.3,3.5,1.0 \mathrm{~Hz}, 1 \mathrm{H}, \mathrm{H}-3), 3.47$ (dd, $J=12.3,2.9 \mathrm{~Hz}$, $1 \mathrm{H}, \mathrm{H}-3), 3.61(\mathrm{dd}, J=2.5,1.0 \mathrm{~Hz}, 1 \mathrm{H}, \mathrm{H}-1), 4.91$ (ddd, $J=7.2,3.1,3.1 \mathrm{~Hz}, 1 \mathrm{H}, \mathrm{H}-4), 5.00(\mathrm{dd}, J=7.2,2.4 \mathrm{~Hz}, 1 \mathrm{H}$, $\mathrm{H}-8) \mathrm{ppm} ;{ }^{13} \mathrm{C} \mathrm{NMR}\left(\mathrm{CDCl}_{3}, 100 \mathrm{MHz}\right): \delta=23.94\left(\mathrm{CH}_{2}\right)$, $25.27\left(2 \mathrm{CH}_{2}\right), 27.41,28.60\left(2 \mathrm{CH}_{3}\right), 41.97\left(\mathrm{SO}_{2} \mathrm{CH}_{3}\right), 48.28$ $\left(2 \mathrm{NCH}_{2}\right), 51.99(\mathrm{C}-4), 60.03(\mathrm{C}-3), 62.07(\mathrm{C}-6), 68.17$ (C-1), 93.91 (C-8), 150.52 (C-7) ppm; IR (KBr): $\bar{v}=2929$, $1626,1323,1307,1158,1135,1113,1048,951 \mathrm{~cm}^{-1}$; HRMS $\left(\mathrm{EI}^{+}\right): \mathrm{m} / z$ calcd. $\mathrm{C}_{14} \mathrm{H}_{24} \mathrm{~N}_{2} \mathrm{O}_{4} \mathrm{~S}_{2}\left(\mathrm{M}^{+}\right)$348.1177, found 348.1159; $\mathrm{C}_{13} \mathrm{H}_{21} \mathrm{~N}_{2} \mathrm{O}_{2} \mathrm{~S}\left(\left[\mathrm{M}-\mathrm{SO}_{2} \mathrm{CH}_{3}\right]^{+}\right)$269.1324, found 269.1322 .

\section{Crystal structure determination of $10 \mathrm{c}$}

All the measurements were performed using monochromatized Mo $\mathrm{K}_{\mathrm{a}}$ radiation at $100 \mathrm{~K}: \mathrm{C}_{14} \mathrm{H}_{24} \mathrm{~N}_{2} \mathrm{O}_{4} \mathrm{~S}_{2}$, $M_{\mathrm{r}}=348.47$, triclinic, space group P-1, $a=8.0619(5) \AA$, $b=13.2727(9) \AA, c=17.2612(11) \AA, \alpha=69.741(2)^{\circ}$, 
$\beta=79.835(3)^{\circ}, \gamma=74.979(2)^{\circ}, V=1665.85(19) \AA^{3}, Z=4$, $d_{\text {calc }}=1.389 \mathrm{~g} \mathrm{~cm}^{-3}, \mu=0.338 \mathrm{~mm}^{-1}$. A total of 148,525 reflections were collected $\left(\Theta_{\max }=40.0^{\circ}\right)$, from which 20,631 were unique $\left(\mathrm{R}_{\mathrm{int}}=0.0388\right)$, with 17,166 having $I>2 \sigma(I)$. The structure was solved by direct methods (SHELXS-97) [22] and refined by full-matrix least-squares techniques against $F^{2}$ (SHELXL-2014/6) [23]. The non-hydrogen atoms were refined with anisotropic displacement parameters without any constraints. The $\mathrm{H}$ atoms of the tertiary $\mathrm{C}-\mathrm{H}$ groups were refined with individual isotropic displacement parameter and all $\mathrm{X}-\mathrm{C}-\mathrm{H}$ angles equal at a $\mathrm{C}-\mathrm{H}$ distance of $1.00 \AA$. The $\mathrm{H}$ atoms of the $\mathrm{CH}_{2}$ groups were refined with common isotropic displacement parameters for the $\mathrm{H}$ atoms of the same group and idealized geometry with approximately tetrahedral angles and $\mathrm{C}-\mathrm{H}$ distances of $0.99 \AA$. The $\mathrm{H}$ atoms $\mathrm{H} 18$ and $\mathrm{H} 28$ were put at the external bisectors of the $\mathrm{C}-\mathrm{C}-\mathrm{C}$ angle at a $\mathrm{C}-\mathrm{H}$ distance of $0.95 \AA$ but the individual isotropic displacement parameters were free to refine. The $\mathrm{H}$ atoms of the methyl groups were refined with common isotropic displacement parameters for the $\mathrm{H}$ atoms of the same group and idealized geometries with tetrahedral angles, enabling rotations around the $\mathrm{C}-\mathrm{C}$ bonds, and C-H distances of $0.98 \AA$. For 427 parameters final $R$ indices of $\mathrm{R} 1=0.0300$ and $\mathrm{wR}^{2}=0.0870(\mathrm{GOF}=1.050)$ were obtained. The largest peak in a difference Fourier map was

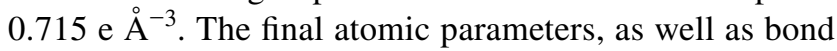
lengths and angles are deposited at the Cambridge Crystallographic Data Centre (CCDC 2,065,356).

(2E)-N-[3-(Azepan-1-yl)-5-methylhexa-2,4-dien-1-ylidene]methanesulfonamide ( $3 \mathrm{~d}, \mathrm{C}_{14} \mathrm{H}_{24} \mathrm{~N}_{2} \mathrm{O}_{2} \mathrm{~S}$ ) Reaction of $741 \mathrm{mg}$ of $1 \mathbf{d}(3.59 \mathrm{mmol})$ in $38 \mathrm{~cm}^{3}$ of $\mathrm{CH}_{2} \mathrm{Cl}_{2}$ with $432 \mathrm{mg}$ of methanesulfonyl chloride $(3.78 \mathrm{mmol})$ in the presence of $1.09 \mathrm{~g}$ of TEA (10.8 $\mathrm{mmol})$ yielded after $2 \mathrm{~d}$ a residue which was purified by $\mathrm{CC}$ over basic aluminum oxide using $\left(\mathrm{CH}_{2} \mathrm{Cl}_{2}: \mathrm{MeOH}=70: 1\right)$ as eluent. Fractions containing 3d were combined and evaporated. A second $\mathrm{CC}$ of the residue over silica gel using $\left(\mathrm{CH}_{2} \mathrm{Cl}_{2}: \mathrm{MeOH}=70: 1\right)$ followed. Fractions containing the product $\mathbf{3 d}$ were combined and evaporated. Yield: $149 \mathrm{mg}$ (15\%) of $\mathbf{3 d}$ as colorless resin. $R_{\mathrm{f}}=0.34$ $\left(\mathrm{CH}_{2} \mathrm{Cl}_{2}: \mathrm{MeOH}=30: 1\right)$; ${ }^{1} \mathrm{H}$ NMR $\left(\mathrm{CDCl}_{3}, 400 \mathrm{MHz}\right)$ : $\delta=1.47-1.73\left(\mathrm{~m}, 6 \mathrm{H}, 3 \mathrm{CH}_{2}\right), 1.68\left(\mathrm{~d}, J=1.3 \mathrm{~Hz}, 3 \mathrm{H}, \mathrm{CH}_{3}\right)$, 1.75-1.89 (m, 2H, $\left.\mathrm{CH}_{2}\right), 1.94\left(\mathrm{~d}, J=1.5 \mathrm{~Hz}, 3 \mathrm{H}, \mathrm{CH}_{3}\right)$, $2.93\left(\mathrm{~s}, 3 \mathrm{H}, \mathrm{SO}_{2} \mathrm{CH}_{3}\right), 3.46-3.58\left(\mathrm{~m}, 4 \mathrm{H}, 2 \mathrm{NCH}_{2}\right), 5.52(\mathrm{~d}$, $J=10.8 \mathrm{~Hz}, 1 \mathrm{H}, \mathrm{H}-2), 5.73$ (t, $J=1.4 \mathrm{~Hz}, 1 \mathrm{H}, \mathrm{H}-4), 8.37$ (d, $J=10.8 \mathrm{~Hz}, 1 \mathrm{H}, \mathrm{H}-1) \mathrm{ppm} ;{ }^{13} \mathrm{C} \mathrm{NMR}\left(\mathrm{CDCl}_{3}, 100 \mathrm{MHz}\right)$ : $\delta=20.39\left(\mathrm{CH}_{3}\right), 25.39\left(\mathrm{CH}_{3}\right), 25.64,25.89,26.92,29.12$ $\left(4 \mathrm{CH}_{2}\right), 41.20\left(\mathrm{SO}_{2} \mathrm{CH}_{3}\right), 50.54,52.02\left(2 \mathrm{NCH}_{2}\right), 96.42$ (C-2), 116.59 (C-4), 144.46 (C-5), 166.45 (C-3), 169.39 (C-1) ppm; IR (KBr): $\bar{v}=2920,1553,1352,1311,1293$, 1246, 1121, 967, 956, 809, $796 \mathrm{~cm}^{-1}$; HRMS (HESI): $\mathrm{m} / \mathrm{z}$ calcd. $\mathrm{C}_{14} \mathrm{H}_{25} \mathrm{~N}_{2} \mathrm{O}_{2} \mathrm{~S}^{+}\left([\mathrm{M}+\mathrm{H}]^{+}\right)$285.1637, found 285.1629 .
(2E)-4-Chloro-N-[5-methyl-3-(piperidin-1-yl)hexa-2,4-dien-1-ylidene]benzene-1-sulfonamide (4c, $\left.\mathrm{C}_{18} \mathrm{H}_{23} \mathrm{CIN}_{2} \mathrm{O}_{2} \mathrm{~S}\right)$ Reaction of $1 \mathrm{~g}$ of $1 \mathrm{c}(5.20 \mathrm{mmol})$ in 51 $\mathrm{cm}^{3}$ of $\mathrm{CH}_{2} \mathrm{Cl}_{2}$ with $1.152 \mathrm{~g}$ of 4-chlorobenzene-1-sulfonyl chloride $(5.46 \mathrm{mmol})$ in the presence of $5.262 \mathrm{~g}$ of TEA (52 mmol) yielded after $2 \mathrm{~d}$ a residue which was purified by $\mathrm{CC}$ using $\left(\mathrm{CH}_{2} \mathrm{Cl}_{2}: \mathrm{MeOH}=30: 1\right)$ as eluent. Fractions containing $\mathbf{4 c}$ were combined and evaporated. The residue was recrystallized twice from ethyl acetate/cyclohexane and once from ethanol. Yield: $220 \mathrm{mg}(12 \%)$ of $\mathbf{4 c}$ as off-white needles. $R_{\mathrm{f}}=0.35\left(\mathrm{CH}_{2} \mathrm{Cl}_{2}: \mathrm{MeOH}=30: 1\right)$; m.p.: $236{ }^{\circ} \mathrm{C} ;{ }^{1} \mathrm{H}$ NMR (DMSO- $\left.d_{6}, 400 \mathrm{MHz}\right): \delta=1.36-1.64\left(\mathrm{~m}, 6 \mathrm{H}, 3 \mathrm{CH}_{2}\right)$ $1.49\left(\mathrm{~s}, 3 \mathrm{H}, \mathrm{CH}_{3}\right), 1.89\left(\mathrm{~s}, 3 \mathrm{H}, \mathrm{CH}_{3}\right), 3.45-3.58(\mathrm{~m}, 4 \mathrm{H}$, $\left.2 \mathrm{NCH}_{2}\right), 5.63(\mathrm{~d}, J=11.0 \mathrm{~Hz}, 1 \mathrm{H}, \mathrm{H}-2), 5.87$ (s, 1H, H-4), $7.58(\mathrm{~d}, J=8.7 \mathrm{~Hz}, 2 \mathrm{H}, \mathrm{ArH}), 7.68(\mathrm{~d}, J=8.4 \mathrm{~Hz}, 2 \mathrm{H}, \mathrm{ArH})$, $8.13(\mathrm{~d}, J=11.1 \mathrm{~Hz}, 1 \mathrm{H}, \mathrm{H}-1) \mathrm{ppm} ;{ }^{13} \mathrm{C} \mathrm{NMR}$ (DMSO- $d_{6}$, $100 \mathrm{MHz}): \delta=20.15\left(\mathrm{CH}_{3}\right), 23.71\left(\mathrm{CH}_{2}\right), 24.94\left(\mathrm{CH}_{3}\right)$, 25.63, $26.65\left(2 \mathrm{CH}_{2}\right), 47.97,50.65\left(2 \mathrm{NCH}_{2}\right), 96.49(\mathrm{C}-2)$, 117.25 (C-4), 128.23, 129.26 (ArC), 136.60, $141.72\left(\mathrm{ArC}_{\mathrm{q}}\right)$, 143.94 (C-5), 166.45 (C-3), 168.74 (C-1) ppm; IR (KBr): $\bar{v}=2930,1560,1474,1446,1348,1315,1300,1274,1238$, $1145,1087,1019,882,829,810,782,755 \mathrm{~cm}^{-1}$; HRMS $\left(\mathrm{EI}^{+}\right): \mathrm{m} / z$ calcd. $\mathrm{C}_{18} \mathrm{H}_{23} \mathrm{ClN}_{2} \mathrm{O}_{2} \mathrm{~S}\left(\mathrm{M}^{+}\right)$366.1169, found 366.1190 .

(2E)-4-Methyl-N-[5-methyl-3-(pyrrolidin-1-yl)hexa-2,4-dien-1-ylidene]benzenesulfonamide (5b, $\mathrm{C}_{18} \mathrm{H}_{24} \mathrm{~N}_{2} \mathrm{O}_{2} \mathrm{~S}$ ) Reaction of $610 \mathrm{mg}$ of $\mathbf{1 b}$ (3.42 mmol) in 30 $\mathrm{cm}^{3}$ of $\mathrm{CH}_{2} \mathrm{Cl}_{2}$ with $685 \mathrm{mg}$ of 4-methylbenzene-1-sulfonyl chloride $(3.59 \mathrm{mmol})$ in the presence of $1.038 \mathrm{~g}$ of TEA (10.3 mmol) yielded after $3 \mathrm{~d}$ a residue which was purified by $\mathrm{CC}$ using $\left(\mathrm{CH}_{2} \mathrm{Cl}_{2}: \mathrm{MeOH}=30: 1\right)$ as eluent. Fractions containing $\mathbf{5 b}$ were combined and evaporated. The residue was recrystallized from ethyl acetate. Yield: $108 \mathrm{mg}(10 \%)$ of $\mathbf{5 b}$ as white needles. $R_{\mathrm{f}}=0.27\left(\mathrm{CH}_{2} \mathrm{Cl}_{2}: \mathrm{MeOH}=30: 1\right)$; m.p.: $117{ }^{\circ} \mathrm{C} ;{ }^{1} \mathrm{H}$ NMR (DMSO- $d_{6}, 400 \mathrm{MHz}$ ): $\delta=1.51$ $\left(\mathrm{d}, J=1.2 \mathrm{~Hz}, 3 \mathrm{H}, \mathrm{CH}_{3}\right), 1.78-1.94\left(\mathrm{~m}, 4 \mathrm{H}, 2 \mathrm{CH}_{2}\right), 1.87$ (d, $\left.J=1.4 \mathrm{~Hz}, 3 \mathrm{H}, \mathrm{CH}_{3}\right), 2.33\left(\mathrm{~s}, 3 \mathrm{H}, \mathrm{ArCH}_{3}\right), 3.20-3.57$ $\left(\mathrm{m}, 4 \mathrm{H}, 2 \mathrm{NCH}_{2}\right), 5.27(\mathrm{~d}, J=11.2 \mathrm{~Hz}, 1 \mathrm{H}, \mathrm{H}-2), 5.90(\mathrm{t}$, $J=1.4 \mathrm{~Hz}, 1 \mathrm{H}, \mathrm{H}-4), 7.31$ (d, J=7.7 Hz, 2H, ArH), 7.55 (d, $J=8.2 \mathrm{~Hz}, 2 \mathrm{H}, \mathrm{ArH}), 8.07$ (d, $J=11.2 \mathrm{~Hz}, 1 \mathrm{H}, \mathrm{H}-1) \mathrm{ppm}$; ${ }^{13} \mathrm{C}$ NMR (DMSO- $\left.d_{6}, 100 \mathrm{MHz}\right): \delta=20.17\left(\mathrm{CH}_{3}\right), 21.08$ $\left(\mathrm{ArCH}_{3}\right), 24.50,24.76\left(2 \mathrm{CH}_{2}\right), 25.05\left(\mathrm{CH}_{3}\right), 48.71,50.14$ $\left(2 \mathrm{NCH}_{2}\right), 96.87$ (C-2), 117.77 (C-4), 126.32, 129.50 (ArC), 139.89, $141.89\left(\mathrm{ArC}_{\mathrm{q}}\right), 143.12$ (C-5), 164.75 (C-3), 166.93 (C-1) ppm; IR (KBr): $\bar{v}=2868,1552,1455,1427,1350$, 1319, 1295, 1284, 1236, 1146, 1085, 884, 814, $783 \mathrm{~cm}^{-1}$; HRMS $\left(\mathrm{EI}^{+}\right): m / z$ calcd. $\mathrm{C}_{18} \mathrm{H}_{24} \mathrm{~N}_{2} \mathrm{O}_{2} \mathrm{~S}\left(\mathrm{M}^{+}\right) 332.1559$, found 332.1575 .

(2E) - N- [ 1 - (Benzenesulfonylimino) - 5 - methylhexa-2,4-dien-3-yl]piperidin-1-ium chloride (6c, $\left.\mathrm{C}_{18} \mathrm{H}_{25} \mathrm{CIN}_{2} \mathrm{O}_{2} \mathrm{~S}\right)$ Reaction of $589 \mathrm{mg}$ of $\mathbf{1 c}(3.06 \mathrm{mmol})$ in 
$30 \mathrm{~cm}^{3}$ of $\mathrm{CH}_{2} \mathrm{Cl}_{2}$ with $579 \mathrm{mg}$ of benzenesulfonyl chloride (3.28 mmol) yielded after $5 \mathrm{~d}$ a residue which was purified by $\mathrm{CC}$ using $\left(\mathrm{CH}_{2} \mathrm{Cl}_{2}: \mathrm{MeOH}=20: 1\right)$ as eluent. Fractions containing $\mathbf{6 c}$ were combined and evaporated and the residue subjected to $\mathrm{CC}$ with $\left(\mathrm{CH}_{2} \mathrm{Cl}_{2}: \mathrm{MeOH}=9: 1\right)$ as eluent. Fractions containing only $\mathbf{6 c}$ were combined and evaporated and the residue was recrystallized from ethanol/ethyl acetate giving $31 \mathrm{mg}$ of $\mathbf{6 c}$. Impure fractions containing $\mathbf{6 c}$ were combined, evaporated and the residue purified using $\mathrm{CC}$ with $\left(\mathrm{CH}_{2} \mathrm{Cl}_{2}: \mathrm{MeOH}=9: 1\right)$ as eluent giving a yellow resin which was recrystallized from ethanol/ethyl acetate and subsequently from ethanol giving additional $35 \mathrm{mg}$ of 6c. Total yield: $66 \mathrm{mg}(6 \%)$ of $\mathbf{6 c}$ as pale orange needles. $R_{\mathrm{f}}=0.78\left(\mathrm{CH}_{2} \mathrm{Cl}_{2}: \mathrm{MeOH}=9: 1\right) ;$ m.p.: $118{ }^{\circ} \mathrm{C}(\mathrm{EtOH}) ;{ }^{1} \mathrm{H}$ NMR ( $\left.\mathrm{CDCl}_{3}, 400 \mathrm{MHz}\right): \delta=1.46-1.73\left(\mathrm{~m}, 6 \mathrm{H}, 3 \mathrm{CH}_{2}\right) 1.62$ (s, $\left.3 \mathrm{H}, \mathrm{CH}_{3}\right), 1.95$ (s, $\left.3 \mathrm{H}, \mathrm{CH}_{3}\right), 3.47$ (br, s, $4 \mathrm{H}, 2 \mathrm{NCH}_{2}$ ), $5.61(\mathrm{~d}, J=10.8 \mathrm{~Hz}, 1 \mathrm{H}, \mathrm{H}-2), 5.70(\mathrm{~s}, 1 \mathrm{H}, \mathrm{H}-4), 7.41-7.48$ (m, 3H, ArH), 7.88 (dd, J=7.9, $1.7 \mathrm{~Hz}, 2 \mathrm{H}, \mathrm{ArH}), 8.43$ (d, $J=10.8 \mathrm{~Hz}, 1 \mathrm{H}, \mathrm{H}-1) \mathrm{ppm} ;{ }^{13} \mathrm{C} \mathrm{NMR}\left(\mathrm{CDCl}_{3}, 100 \mathrm{MHz}\right)$ : $\delta=20.30\left(\mathrm{CH}_{3}\right), 24.10\left(\mathrm{CH}_{2}\right), 25.42\left(\mathrm{CH}_{2}, \mathrm{CH}_{3}\right), 26.70$ $\left(\mathrm{CH}_{2}\right), 48.02,50.50\left(2 \mathrm{NCH}_{2}\right), 97.37(\mathrm{C}-2), 116.86(\mathrm{C}-4)$, 126.74, 128.58, $131.52(\mathrm{ArC}), 142.08\left(\mathrm{ArC}_{\mathrm{q}}\right), 145.16(\mathrm{C}-5)$, 165.55 (C-3), 169.57 (C-1) ppm; IR (KBr): $\bar{v}=2935,1555$, 1445, 1351, 1317, 1282, 1238, 1142, 1086, 1019, 881, 811, 784, 764, $724 \mathrm{~cm}^{-1}$; HRMS $\left(\mathrm{EI}^{+}\right): \mathrm{m} / z$ calcd. $\mathrm{C}_{18} \mathrm{H}_{24} \mathrm{~N}_{2} \mathrm{O}_{2} \mathrm{~S}$ $\left([\mathrm{M}-\mathrm{HCl}]^{+}\right) 332.1559$, found 332.1564 .

(2E)- $N$-[5-Methyl-1-(4-nitrobenzenesulfonylimino)hexa-2,4-dien-3-yl]pyrrolidine-1-ium chloride (7b, $\left.\mathrm{C}_{17} \mathrm{H}_{22} \mathrm{ClN}_{3} \mathrm{O}_{4} \mathrm{~S}\right)$ Reaction of $547 \mathrm{mg}$ of $\mathbf{1 b}(3.07 \mathrm{mmol})$ in 30 $\mathrm{cm}^{3}$ of $\mathrm{CH}_{2} \mathrm{Cl}_{2}$ with $714 \mathrm{mg}$ of 4-nitrobenzenesulfonyl chloride $(3.22 \mathrm{mmol}$ ) yielded after $4 \mathrm{~d}$ a reaction mixture. Ethyl acetate was added with stirring and the solid was sucked off, washed with ethyl acetate, and purified using CC with $\left(\mathrm{CH}_{2} \mathrm{Cl}_{2}: \mathrm{MeOH}=9: 1\right)$ as eluent giving a yellow solid. Yield: $50 \mathrm{mg} \mathrm{(4 \% )}$ of $\mathbf{7 b}$. For analytical purposes it was dissolved in $\mathrm{CHCl}_{3}$, filtered, the solvent evaporated, and the residue recrystallized from ethanol giving fine-particle yellow needles. $R_{\mathrm{f}}=0.87\left(\mathrm{CH}_{2} \mathrm{Cl}_{2}: \mathrm{MeOH}=9: 1\right)$; m.p.: $192{ }^{\circ} \mathrm{C}(\mathrm{EtOH})$; ${ }^{1} \mathrm{H} \mathrm{NMR}\left(\mathrm{CDCl}_{3}, 400 \mathrm{MHz}\right): \delta=1.68\left(\mathrm{~s}, 3 \mathrm{H}, \mathrm{CH}_{3}\right), 1.97$ (br, s, 5H, $\mathrm{CH}_{2}, \mathrm{CH}_{3}$ ), 2.04-2.08 (m, 2H, $\left.\mathrm{CH}_{2}\right), 3.38-3.59$ $\left(\mathrm{m}, 4 \mathrm{H}, 2 \mathrm{NCH}_{2}\right), 5.46(\mathrm{~d}, J=11.0 \mathrm{~Hz}, 1 \mathrm{H}, \mathrm{H}-2), 5.78(\mathrm{~s}$, $1 \mathrm{H}, \mathrm{H}-4), 8.05(\mathrm{~d}, J=8.8 \mathrm{~Hz}, 2 \mathrm{H}, \mathrm{ArH}), 8.27(\mathrm{~d}, J=8.8 \mathrm{~Hz}$, $2 \mathrm{H}, \mathrm{ArH}), 8.37$ (d, $J=11.0 \mathrm{~Hz}, 1 \mathrm{H}, \mathrm{H}-1) \mathrm{ppm} ;{ }^{13} \mathrm{C} \mathrm{NMR}$ $\left(\mathrm{CDCl}_{3}, 100 \mathrm{MHz}\right): \delta=20.47\left(\mathrm{CH}_{3}\right), 24.76\left(\mathrm{CH}_{2}\right), 25.03$ $\left(\mathrm{CH}_{3}\right), 25.53\left(\mathrm{CH}_{2}\right), 48.84,50.35\left(2 \mathrm{NCH}_{2}\right), 98.79(\mathrm{C}-2)$, 116.98 (C-4), 123.86, 127.85 (ArC), 144.94 (C-5), 148.46, 149.22 ( $\left.\mathrm{ArC}_{\mathrm{q}}\right), 165.63$ (C-3), 168.25 (C-1) ppm; IR (KBr): $\bar{v}=2976,1561,1525,1349,1290,1256,1146,1084,895$, $794,740 \mathrm{~cm}^{-1}$; HRMS (EI $\left.{ }^{+}\right): \mathrm{m} / z$ calcd. $\mathrm{C}_{17} \mathrm{H}_{21} \mathrm{~N}_{3} \mathrm{O}_{4} \mathrm{~S}([\mathrm{M}-$ $\mathrm{HCl}]^{+}$) 363.1253, found 363.1272.
(2E)-N-[5-Methyl-1-(4-nitrobenzenesulfonylimino)hexa-2,4-dien-3-yl]piperidin-1-ium chloride (7c, $\left.\mathrm{C}_{18} \mathrm{H}_{24} \mathrm{CIN}_{3} \mathrm{O}_{4} \mathrm{~S}\right)$ Reaction of $589 \mathrm{mg}$ of $1 \mathrm{c}(3.06 \mathrm{mmol})$ in $30 \mathrm{~cm}^{3}$ of $\mathrm{CH}_{2} \mathrm{Cl}_{2}$ with $712 \mathrm{mg}$ of 4-nitrobenzenesulfonyl chloride $(3.21 \mathrm{mmol})$ yielded after $5 \mathrm{~d}$ a reaction mixture. Ethyl acetate was added with stirring and the solid was sucked off, washed with ethyl acetate, and purified using $\mathrm{CC}$ with $\left(\mathrm{CH}_{2} \mathrm{Cl}_{2}: \mathrm{MeOH}=9: 1\right)$ as eluent giving a yellow solid. Yield: $262 \mathrm{mg}$ (21\%) of 7c. For analytical purposes it was dissolved in $\mathrm{CHCl}_{3}$, filtered, the solvent evaporated, and the residue recrystallized from ethanol giving yellow needles. $R_{\mathrm{f}}=0.84\left(\mathrm{CH}_{2} \mathrm{Cl}_{2}: \mathrm{MeOH}=9: 1\right)$; m.p.: $183{ }^{\circ} \mathrm{C}$ $(\mathrm{EtOH}) ;{ }^{1} \mathrm{H}$ NMR $\left(\mathrm{CDCl}_{3}, 400 \mathrm{MHz}\right): \delta=1.50-1.74(\mathrm{~m}$, $\left.6 \mathrm{H}, 3 \mathrm{CH}_{2}\right), 1.66\left(\mathrm{~s}, 3 \mathrm{H}, \mathrm{CH}_{3}\right), 1.99\left(\mathrm{~s}, 3 \mathrm{H}, \mathrm{CH}_{3}\right), 3.50-3.53$ $\left(\mathrm{m}, 4 \mathrm{H}, 2 \mathrm{NCH}_{2}\right), 5.67(\mathrm{~d}, J=11.0 \mathrm{~Hz}, 1 \mathrm{H}, \mathrm{H}-2), 5.73(\mathrm{~s}$, $1 \mathrm{H}, \mathrm{H}-4), 8.05$ (d, $J=9.2 \mathrm{~Hz}, 2 \mathrm{H}, \mathrm{ArH}), 8.28$ (d, $J=8.8 \mathrm{~Hz}$, $2 \mathrm{H}, \mathrm{ArH}), 8.41(\mathrm{~d}, J=11.0 \mathrm{~Hz}, 1 \mathrm{H}, \mathrm{H}-1) \mathrm{ppm} ;{ }^{13} \mathrm{C} \mathrm{NMR}$ $\left(\mathrm{CDCl}_{3}, 100 \mathrm{MHz}\right): \delta=20.38\left(\mathrm{CH}_{3}\right), 23.94\left(\mathrm{CH}_{2}\right), 25.43$ $\left(\mathrm{CH}_{3}\right), 25.50,26.76\left(2 \mathrm{CH}_{2}\right), 48.36,50.88\left(2 \mathrm{NCH}_{2}\right), 97.86$ (C-2), 116.49 (C-4), 123.83, 127.82 (ArC), 145.72 (C-5), 148.38, $149.19\left(\mathrm{ArC}_{\mathrm{q}}\right), 166.66$ (C-3), 169.65 (C-1) ppm; IR (KBr): $\bar{v}=2940,1552,1446,1346,1294,1241,1148$, 1085, 889, 817, 782, $739 \mathrm{~cm}^{-1}$; HRMS $\left(\mathrm{EI}^{+}\right): \mathrm{m} / \mathrm{z}$ calcd. $\mathrm{C}_{18} \mathrm{H}_{23} \mathrm{~N}_{3} \mathrm{O}_{4} \mathrm{~S}\left([\mathrm{M}-\mathrm{HCl}]^{+}\right)$377.1409, found 377.1387; calcd. $\mathrm{C}_{17} \mathrm{H}_{20} \mathrm{~N}_{3} \mathrm{O}_{4} \mathrm{~S}\left(\left[\mathrm{M}-\mathrm{HCl}-\mathrm{CH}_{3}\right]^{+}\right)$362.1175, found 362.1168 .

(2E)-N-[4-Chloro-5-methyl-3-(pyrrolidin-1-yl)hexa-2,4-dien-1-ylidene]benzenesulfonamide (8b, $\left.\mathrm{C}_{17} \mathrm{H}_{21} \mathrm{CIN}_{2} \mathrm{O}_{2} \mathrm{~S}\right)$ The reaction of $2.57 \mathrm{~g}$ of $\mathbf{1 b}(14.42 \mathrm{mmol})$ in $120 \mathrm{~cm}^{3}$ of $\mathrm{CH}_{2} \mathrm{Cl}_{2}$ with $2.548 \mathrm{~g}$ of benzenesulfonyl chloride $(14.43 \mathrm{mmol})$ in the presence of $1.46 \mathrm{~g}$ of TEA (14.41 mmol) was started at $-70{ }^{\circ} \mathrm{C}$ (solid $\mathrm{CO}_{2} / 2$-propanol) and the reaction batch was allowed to come up to room temperature. It was stirred for $2 \mathrm{~d}$. After workup according to the synthesis of $\mathbf{2 b}$ a residue was yielded which was purified by treatment with charcoal and subsequent by $\mathrm{CC}$ using $\left(\mathrm{CH}_{2} \mathrm{Cl}_{2}: \mathrm{MeOH}=39: 1\right)$ as eluent giving an orange resin. The slightly impure fractions were combined, evaporated, and the residue recrystallized repeatedly yielding additional product as off-white needles. Yield: $317 \mathrm{mg}(6 \%)$ of $\mathbf{8 b} . R_{\mathrm{f}}=0.12$ $\left(\mathrm{CH}_{2} \mathrm{Cl}_{2}: \mathrm{MeOH}=60: 1\right)$; m.p.: $127{ }^{\circ} \mathrm{C} ;{ }^{1} \mathrm{H} \mathrm{NMR}\left(\mathrm{CDCl}_{3}\right.$, $400 \mathrm{MHz}): \delta=1.71\left(\mathrm{~s}, 3 \mathrm{H}, \mathrm{CH}_{3}\right), 1.92-2.10\left(\mathrm{~m}, 4 \mathrm{H}, 2 \mathrm{CH}_{2}\right)$ $2.00\left(\mathrm{~s}, 3 \mathrm{H}, \mathrm{CH}_{3}\right), 3.28-3.40\left(\mathrm{~m}, 3 \mathrm{H}, \mathrm{NCH}_{2}\right), 3.57-3.64$ $\left(\mathrm{m}, 1 \mathrm{H}, \mathrm{NCH}_{2}\right), 5.38$ (d, $\left.J=10.6 \mathrm{~Hz}, 1 \mathrm{H}, \mathrm{H}-2\right), 7.43-7.52$ (m, 3H, ArH), 7.88 (dd, $J=8.4,1.5 \mathrm{~Hz}, 2 \mathrm{H}, \mathrm{ArH}), 8.38$ (d, $J=11.0 \mathrm{~Hz}, 1 \mathrm{H}, \mathrm{H}-1) \mathrm{ppm} ;{ }^{13} \mathrm{C} \mathrm{NMR}\left(\mathrm{CDCl}_{3}, 100 \mathrm{MHz}\right)$ : $\delta=20.71\left(\mathrm{CH}_{3}\right), 21.57\left(\mathrm{CH}_{3}\right), 24.82,25.04\left(2 \mathrm{CH}_{2}\right), 48.68$, $49.60\left(2 \mathrm{NCH}_{2}\right), 97.36(\mathrm{C}-2), 115.28(\mathrm{C}-4), 126.91,128.69$, 131.88 (ArC), 137.63 (C-5), $141.33\left(\mathrm{ArC}_{\mathrm{q}}\right), 162.14$ (C-3), 167.15 (C-1) ppm; IR (KBr): $\bar{v}=2871,1560,1448,1425$, 1354, 1320, 1298, 1285, 1243, 1142, 1084, 847, 826, 797, $723 \mathrm{~cm}^{-1}$; HRMS $\left(\mathrm{EI}^{+}\right): \mathrm{m} / z$ calcd. $\mathrm{C}_{17} \mathrm{H}_{21} \mathrm{ClN}_{2} \mathrm{O}_{2} \mathrm{~S}\left(\mathrm{M}^{+}\right)$ 352.1012, found 352.1035; HRMS (MALDI): $\mathrm{m} / \mathrm{z}$ calcd. 
$\mathrm{C}_{17} \mathrm{H}_{21} \mathrm{ClN}_{2} \mathrm{NaO}_{2} \mathrm{~S}\left([\mathrm{M}+\mathrm{Na}]^{+}\right)$375.0910, found 375.0934; calcd. $\mathrm{C}_{17} \mathrm{H}_{22} \mathrm{ClN}_{2} \mathrm{O}_{2} \mathrm{~S}\left([\mathrm{M}+\mathrm{H}]^{+}\right)$353.1090, found 353.1066 .

( $1 Z$ ) - 1 - [ 1 - (Benzenesulfonamido) - 5 - methylhexa-1,4-dien-3-ylidene]pyrrolidin-1-ium chloride (9b, $\mathrm{C}_{17} \mathrm{H}_{23} \mathrm{CIN}_{2} \mathrm{O}_{2} \mathrm{~S}$ ) Compound $2 \mathrm{~b}(125 \mathrm{mg}, 0.39 \mathrm{mmol})$ was dissolved in $\mathrm{CH}_{2} \mathrm{Cl}_{2}$ and treated with an excess of $1.25 \mathrm{M}$ ethanolic $\mathrm{HCl}\left(0.63 \mathrm{~cm}^{3}, 0.78 \mathrm{mmol}\right)$. The solvent was evaporated in vacuo and the residue was crystallized from ethanol. The first precipitate was filtered with suction, washed with ethanol, and discarded. To the mother liquor diethyl ether was added until crystallization seemed to be complete. This second precipitate was filtered with suction, washed with diethyl ether, and dried in vacuo. Yield: $37 \mathrm{mg}(27 \%)$ of 9b as white powder. $R_{\mathrm{f}}=0.90\left(\mathrm{CH}_{2} \mathrm{Cl}_{2}: \mathrm{MeOH}=9: 1\right)$; m.p.: $146{ }^{\circ} \mathrm{C} ;{ }^{1} \mathrm{H} \mathrm{NMR}\left(\mathrm{CDCl}_{3}, 400 \mathrm{MHz}\right): \delta=1.60\left(\mathrm{~s}, 3 \mathrm{H}, \mathrm{CH}_{3}\right)$, 2.04 (s, 3H, $\mathrm{CH}_{3}$ ), 2.09-2.17 (m, 4H, 2CH $), 3.74$ (br, s, $2 \mathrm{H}$, $\mathrm{NCH}_{2}$ ), 3.85 (br, s, 2H, $\mathrm{NCH}_{2}$ ), 5.98 (s, 1H, H-4), 6.80 (d, $J=12.8 \mathrm{~Hz}, 1 \mathrm{H}, \mathrm{H}-2), 7.53-7.63$ (m, 4H, H-1, ArH), 8.02 (d, $J=7.3 \mathrm{~Hz}, 2 \mathrm{H}, \mathrm{ArH}) \mathrm{ppm} ;{ }^{13} \mathrm{C} \mathrm{NMR}\left(\mathrm{CDCl}_{3}, 100 \mathrm{MHz}\right)$ : $\delta=21.09\left(\mathrm{CH}_{3}\right), 24.46,24.64\left(2 \mathrm{CH}_{2}\right), 25.80\left(\mathrm{CH}_{3}\right), 51.78$, $53.12\left(2 \mathrm{NCH}_{2}\right), 101.19(\mathrm{C}-2), 115.85(\mathrm{C}-4), 126.92,129.33$, 133.61 (ArC), $139.25\left(\mathrm{ArC}_{\mathrm{q}}\right), 148.98$ (C-5), 152.23 (C-1), 170.06 (C-3) ppm; IR (KBr): $\bar{v}=2597,1615,1589,1446$, 1386, 1352, 1307, 1243, 1168, 1087, 892, 843, 812, 788, $761,724 \mathrm{~cm}^{-1}$; HRMS $\left(\mathrm{EI}^{+}\right): \mathrm{m} / z$ calcd. $\mathrm{C}_{17} \mathrm{H}_{22} \mathrm{~N}_{2} \mathrm{O}_{2} \mathrm{~S}([\mathrm{M}-$ $\mathrm{HCl}]^{+}$) 318.1402, found 318.1418.

\section{In vitro antiprotozoal assays and cytotoxicity}

The in vitro growth inhibition assay of Plasmodium falciparum NF54 and the in vitro growth inhibition assay of Trypanosoma $b$. rhodesiense, as well as the assay for the determination of cytotoxicity against L6-cells were performed as described earlier [24].

\section{Cytotoxicity against human CCRF-CEM leukemia cells}

The cell culture of CCRF-CEM cells and XTT viability assay were operated as described previously [15].

\section{Detection of antimicrobial activity}

Drop plate methods [25] with modification were performed to detect the antimicrobial activity against two Gram-positive strains, two Gram-negative strains, and one yeast strain from accredit source. All compounds were dissolved in DMSO to a concentration of $1 \mathrm{mg} / \mathrm{cm}^{3}$. Using sterile micropipette $10 \mathrm{~mm}^{3}$ of each compound was directly but gently dropped over seeded agar plate with test organism. The liquid was allowed to diffuse before the plate was inverted and incubated. The growth conditions for every strain were considered. The results were noted when a lawn of the indicator bacteria appeared on the plate (approximately 10-16 h).

Supplementary Information The online version contains supplementary material available at https://doi.org/10.1007/s00706-021-02850-3.

Acknowledgements NAWI Graz is acknowledged for supporting the Graz Central Lab Environmental, Plant and Microbial Metabolomics.

Funding Open access funding provided by University of Graz.

Open Access This article is licensed under a Creative Commons Attribution 4.0 International License, which permits use, sharing, adaptation, distribution and reproduction in any medium or format, as long as you give appropriate credit to the original author(s) and the source, provide a link to the Creative Commons licence, and indicate if changes were made. The images or other third party material in this article are included in the article's Creative Commons licence, unless indicated otherwise in a credit line to the material. If material is not included in the article's Creative Commons licence and your intended use is not permitted by statutory regulation or exceeds the permitted use, you will need to obtain permission directly from the copyright holder. To view a copy of this licence, visit http://creativecommons.org/licenses/by/4.0/.

\section{References}

1. Zhou L, Yuan C, Zeng Y, Liu H, Wang C, Gao X, Wang Q, Zhang C, Guo H (2018) Chem Sci 9:1831

2. Ewies EF, El-Hag FAA (2020) J Heterocycl Chem 57:163

3. Jalali H, Hosseini SJ, Ali-Asgari S, Nia JI (2020) J Heterocycl Chem 57:419

4. Capretz-Agy A, Fernandes FS, Rodrigues MT, Conti C, Coelho F (2019) Synlett 30:A-E

5. Gu Z, Wu B, Jiang G-F, Zhou Y-G (2018) Chin J Chem 36:1130

6. Laha JK, Krupal PJ, Tummalapalli KSS, Sharma S (2017) Eur J Org Chem 4617

7. Wang L, Wu H, Ding R, Chen Z, Jin Y (2019) Curr Org Chem 23:1688

8. Schnermann MJ, Romero FA, Hwang I, Nakamura-Ogiso E, Yagi T, Boger DL (2006) J Am Chem Soc 128:11799

9. Nocket AJ, Weinreb SM (2014) Angew Chem Int Ed 53:14162

10. Carvalho MFNN, Leite S, Costa JP, Galvão AM, Leitão JH (2019) J Inorg Biochem 199:110791

11. Chopra A, Singh L, Kapoor VK, Dhingra R, Dhingra N (2019) Int J Pharm Sci Res 10:3073

12. Okajima N, Aoki I, Kuragano T, Okada Y (1991) Pestic Sci 32:91

13. Babczinski P, Zelinski T (1991) Pestic Sci 31:305

14. Cardoso JMS, Correia I, Galvão AM, Marques F, Carvalho MFNN (2017) J Inorg Biochem 166:55

15. Mohsin NA, Seebacher W, Faist J, Hochegger P, Kaiser M, Mäser P, Belaj F, Saf R, Kretschmer N, Alajlani M, Turek I, Brantner A, Bauer R, Bucar F, Weis R (2018) Eur J Med Chem 143:97

16. Mohsin NA, Seebacher W, Hochegger P, Faist J, Saf R, Kaiser M, Mäser P, Weis R (2019) Med Chem Res 28:742

17. Petritsch M, Seebacher W, Mohsin NA, Dolensky J, Hochegger P, Kaiser M, Mäser P, Belaj F, Saf R, Kretschmer N, Alajlani M, Brantner A, Bauer R, Schühly W, Weis R (2021) Eur J Med Chem 210:112969

18. Mohsin NA, Seebacher W, Faist J, Kretschmer N, Bauer R, Saf R, Kaiser M, Mäser P, Weis R (2018) Monatsh Chem 149:801 
19. Seebacher W, Faist J, Belaj F, Saf R, Kaiser M, Brun R, Weis R (2015) Monatsh Chem 146:1299

20. Johnson CK (1965) ORTEP. Report ORNL-3794. Oak Ridge National Laboratory, Tennessee

21. Rostamzadeh Z, Mohammadian M, Rostamzade A (2016) Adv Microbiol 6:190

22. Sheldrick GM (2008) Acta Cryst A64:112

23. Sheldrick GM (2015) Acta Cryst C17:3

24. Mohsin NA, Seebacher W, Faist J, Hochegger P, Kaiser M, Mäser P, Saf R, Weis R (2018) Monatsh Chem 149:99
25. Alajlani M, Shiekh A, Hasnain S, Brantner A (2016) Chromatographia 79:1527

Publisher's Note Springer Nature remains neutral with regard to jurisdictional claims in published maps and institutional affiliations. 